\title{
Teknologi Pembuatan Abon Ikan Lele Bebas Bau Amis (Penyuluhan dan Implementasi)
}

\author{
Ristina Siti Sundari $^{*}$, Andri Kusmayadi², Budhi Wahyu Fitriadi ${ }^{3}$ \\ Universitas Perjuangan Tasikmalaya ${ }^{1,2,3}$ \\ ristina.sitisundari@yahoo.com ${ }^{1 *}$, andrikusmayadi01@gmail.com ${ }^{2}$, budhywf@gmail.com ${ }^{3}$
}

\begin{abstract}
Almost people like any fishes, but some do not like the fish rancid even after processing. Catfish shredded is one of the processed processes. Turmeric, ginger, lemon, tamarind, vinegar, starfruit is often used to eliminate the fishy smell, but it still has taste left by itself. Community service was conducted to empower them and cope with the fishy smell problem. So that modified to the new variance beside the original product. Dan largen market share. Women Farmer Group for fisheries processing produces the object due to extension and implementation to adopt the technology innovation about catfish shredded processing to eliminate rancid on a fish odor. We hope this engagement and empowerment will become sustainable and spread out to other women farmer groups and animal products based on our research to raise economic circles. The group had a pre-test and post-test to measure the understanding and innovation adoption level. This engagement resulted in two variances of catfish by original and rancid free enriched with antioxidant of oregano leaf. The other result is that this new variance has more voluminous than the original in the same weight.
\end{abstract}

Keywords: Catfish shredded; free rancid; technology

\begin{abstract}
Abstrak
Sebagian besar orang menyukai ikan sebagai pangan fungsional, tapi banyak yang tidak menyukai bau amis produk hewani ini, sehingga seringkali membuat sebagian masyarakat enggan untuk mengonsumsinya. Abon ikan termasuk salah satu produk hewani yang dikeluhkan. Hal ini menyebabkan konsumen menjadi enggan memakannya. Jahe, kunyit, jeruk nipis, asam jawa dan belimbing wuluh dapat menekan bau amis namun masih meninggalkan rasa khas bahan aslinya. Pengabdian kepada masyarakat dilakukan untuk mengatasi bau amis pada ikan dalam proses pengolahan abon ikan lele, sehingga diharapkan menambah varian baru dan jangkauan pasarnya makin luas. Kelompok masyarakat pengolah ikan diberi penyuluhan dan implementasinya agar dapat mengadopsi inovasi teknologi pembuatan abon ikan yang bebas bau amis. Proses produksi diharapkan akan berkelanjutan dan meluas pada pengolah ikan dan produk hewani lainnya. Pada kegiatan ini dilakukan juga pre-test dan post-test untuk mengetahui pemahaman dan tingkat adopsi inovasi mitra. Hasil kegiatan pengabdian ini adalah dua varian produk abon ikan lele yaitu abon yang original dan abon yang tidak berbau amis serta diperkaya dengan daun jintan. Hasil lain adalah abon ikan yang diperkaya daun jintan sehinggan tidak amis memenuhi kemasan lebih banyak dibandingkan dengan abon ikan lele original walaupun beratnya sama.
\end{abstract}

Kata Kunci: Abon Lele; Bebas Amis; Teknologi. 


\section{A. PENDAHULUAN}

Universitas Perjuangan Tasikmalaya mengembangkan produk-produk yang berbasis kearifan, baik produk seni, buadaya maupun kekayaan alamnya. Visi dan misinya menciptakan lulusannya menjadi wirausahwan baru di samping dimanfaatkan oleh stakeholder. Hal ini memperoleh dukungan premerintah melalui programprogramnya terutama ditujukan pada generasi milenial. PKM dan UKM masyarakat sekitar dan mahasiswa melalui incubator agribisnis diarahkan untuk berwirausaha. Banyak potensi kearifan lokal yang sangat layak untuk dikembangkan yang seranga populasinya semakin berkurang atau sesuatu yang bagus tetapi belum deknal dengan baik oleh masyarakat. Kearifan lokal sebagai komoditas agribisnis menjadi ciri khas tersendiri yang menjual bahkan bisa berorientasi secara global.

Hal ini semakin mudah jika memperoleh dukungan IT dan media elektronik maupun virtual, menurut (Kotler, 2013) bersentuhan langsung baik produsen maupun konsumen. Pengembangan

komoditas dan sumber daya manusia dan sumber daya alam berpadu serasi agar mencapai peningkatan kesejahteraan dan kebutuhan cukup dipenuhi dari dalamnegeri.

Produk-produk olahan dengan bahan baku ikan lele mulai diminati di hati masyarakat seiring dengan pertambahan penduduk dan aktifitas perkonomian baik lokal maupun di luar daerah bahkan ke luar propinsi dan luar negeri. Produk ekonomi kreatif seperti abon ikan yang bukan terbuat dari daging sapi dan ataupun daging ayam sudah mulai dikembangkan di Tasikmalaya. Abon ikan merupakan produk hasil olahan yang dibuat dari daging ikan, yang dikombinasikan dengan proses penggilingan, penggorengan (Azis et al., 2019; Ismail \&
Putra, 2017) Abon ikan bisa dijual dengan harga yang lebih murah dengan gizi yang sama tinggi dimungkinkan karena bahan bakunya lebih murah (Sundari, Umbara, et al., 2019). Memanfaatkan teknologi dalam pengolahan dan sumber daya lainnya dapat menyesuaikan dengan tingkat kebutuhan serta situasi dan kondisi di masyarakat dan selera pasar (Kotler, 2011a, 2013, 2011b; Kotler \& Keller, 2016).

Produk abon merupakan produk pangan yang siap konsumsi yang praktis dan tahan lama. Sering dijadikan stok di rumah tangga saat emergensi, digunakan sebagai teman nasi atau taburan penganan dan snack atau biscuit serta bekal saat perjalanan jauh seperti piknik, berkunjung, oleh-oleh atau untuk perjalanan spiritual yang membutuhkan waktu lama. Rasanya yang manis dan enak disukai hampir semua kalangan dan mudah dikunyah baik oleh balita ataupun manula.

Usaha perikanan darat Tasikmalaya sudah dikenal sejak lama diantaranya adalah ikan lele. Awalnya kurang disukai karena sering dipelihara di kolam-kolam limbah. Namun seiring pengembangan budidayaikan berkumis ini menjadi pilihan konsumsi yang sudah dijual di restoran sampe warung pinggir jalan.

Kewirausahan yang terus bertumbuh dengan pesat di Tasikmalaya yang dikenal sebagai kota kuliner setelah ibu kota provinsi Jawa Barat yaitu Bandung. Kelompok Wanita Tani Pengolah Ikan "Jaya Mandiri” adalah salah satunya, dimana hasil distribusi hasil produksi melibatkan mahasiswa sebagai reseler sebagai salah satu strategi pemasaran agar perputaran modal berlangsung lebih cepat. Hasil pengabdian sebelumnya berhasil baik dapat memperluas jangkauan pasar dan diusahakan agar dapat berkelanjutan dan melalui inovasi yang terus menerus dalam 
teknologi produk dan sumber daya (Agus, 2012; Husnan 1994).

Masih ada masalah lain yang dihadapi produsen dalam pemasaran abon ikan yaitu selera konsumen. Rasa, tekstur, struktur, warna dapat diterima oleh hampir semua konsumen. Sebagian konsumen masih ada yang mengeluh tentang aroma ikan yang khas yang mereka kurang suka yaitu aroma amisnya masih melekat. Maka Pengabdian kepada masyarakat saat ini adalah memperkenalkan inovasi teknologi yang dapat menghilangkan bau amis yang tidak berasa berbasis hasil penelitian.

Bau amis pada ikan disebabkan terbentuknya reaksi enzimatis dan oksidasi asam amino di dalam tubuh ikan memunculkan dua karakter asam amino. Pertama bersifat mudah menguap (volatile) dan kedua bersifat bertahan dalam tubuhnya (nonvolatile) (Deng dkk, 2014). Yang bersifat volatile memunculkan aroma dan yang bersifat nonvolatile memunculkan rasa gurih (umami). Dengan demikian, semakin tinggi kandungan asam amino dalam ikan maka semakin tajam aroma dan rasanya. Kemudian pada saat mulai proses pembusukan terjadi oksidasi asam amino dengan udara yang merubah baunya menjadi tidak enak serta memancing datangnya mikroorganisma yang dapat mempercepat proses pembusukan. Melalui pengukusan dan perebusan, kadar sebagian besar senyawa asam amino meningkat (Pratama et al., 2018; Prataman et al., 2018). Melalui penggorengan, kadar asam amino cenderung turun tapi masih berbau amis. melalui pemanasan dengan minyak akan mengakibatkan hilangnya asam amino sehingga rasa dan aromanya berkurang. tetapi melalui penambahan zat dari bahan dari herbal tertentu aroma bau amis hilang, rasa tetap utuh tetapi tidak mengurangi kandungan asam amino.
Maka kami merasa perlu melakukan pengabdian ini untuk membantu mengatasi masalah bau amis yang dikeluhkan ini. Sedangkan yang ingin dicapai adalah menciptakan masyarakat kreatif, inovatif dan memiliki motivasi yang tinggi dalam mengembangkan pemasaran produk abon ikan dengan referensi membidik selera konsumen yang menginginkan hilangnyabau amis pada produk barbahan ikan.

\section{B. PELAKSAAAN DAN METODE}

Metode yang digunakan adalah ceramah dan mempraktekkan inovasi teknologi menghilangkan bau amis pada abon ikan. Hasilnya dibandingkan dengan abon ikan original. Selanjutnya diadakan evaluasi tingkat pemahaman masyarakat terhadap inovasi teknologi ini dan implementasinya. Produk inovasi dan Sumber daya manusia dibandingkan Antara sebelum dan sesudah mendapatkan inovasi teknologi menghilangkan bau amis abon ikan.

UMKM pengolahan ikan di Tasikmalaya pada umumnya berskala kecil sehingga dilakukan pembentukan kelompokkelompok pengolahan ikan, seperti halnya kelompok pengolahan ikan menjadi abon ikan. Dengan pengelolaan yang baik dan inovasi yang terus menerus, diharapkan dapat menembus pasar yang lebih luas. Dengan demikian usaha bisa terus dikembangkan menjadi besar.

Pembuatan abon ikan bisa dilakukan walaupun dengan modal kecil. Bahan baku tersedia dan bisa dikerjakan di rumah-rumah. baik oleh laki-laki maupun perempuan. Bisa dimakan oleh semua umur dan bisa menambah selera makan bagi orang yang sakit. Namun demikian, masyarakat meminta bau amisnya dihilangkan maka tingkat konsumsi akan lebih tinggi. 
Kegiatan dimulai dengan melakukan survey ke lokasi untuk menjaring masyarakat pengolah ikan yang akan diberi penyuluhan implementasi inovasi cara menghilangkan bau amis pada produk agroindustry abon ikan. Kemudian Menyiapkan peralatan dan bahan-bahan yang dibutuhkan untuk pengabdian kepada masyarakat. Langsung menyusun jadwal pertemuan dengan masyarakat pengolah ikan di Kelurahan Sukanagara Kecamatan Purbaratu Tasikmalaya. Setelah materi disiapkan sedemikian rupa maka penyuluhan dilaksanakan tentang pentingnya inovasi produk dan varian produk untk megembangkan usaha abon ikan agar bisa digemari oleh masyarakat. Demikian pula kegiatan memberikan penyuluhan inovasi baru tentang teknologi penghilangan bau amis ikan tanpa menghilangkan rasa ikan ataupu terganggu oleh karakter bahan yang dibawanya seperti rasa asam, rasa tannin, pedas, langu dan lain lain. Penyuluhan tentang tanaman-tanaman yang bisa menghilangkan bau amis. Perbanyakan tanaman daun jintan sebagai sumber bahan baku yang dapat menghilangkan bau amis. Setelah diketahui perlakuan penghilangan bau amis, maka kegiatan selanjutnya adalah mempraktekkan teknologi inovasi penghilang bau amis yang sederhana. Setelah inovasi dan teknologi dipraktekkan, maka dilakukan kegiatan membandingkan abon ikan lele yang diperkaya antioksisan dengan abon ikan lele original. Untuk memastikan materi penyuluhan dan implementasi dapat diserap oleh kelompok maka dilakukan evaluasi kegiatan, evaluasi sikap dan pemahaman masyarakat terhadap inovasi teknologi penghilang bau amis. Kemudian Monitor keberlanjutan inovasi.

Proses pembuatan abon ikan lele agar bau amisnya hilang dilakukan sejak ikan lele segar selesai dibersihkan. Dalam tiap kilogram ikan segar hanya sedikit membutuhkan ekstrak daun jintan untuk melenyapkan bau amisnya. Jadi tidak menambah biaya produksi. Di samping itu sudah tersedia di halaman rumah masingmasing.

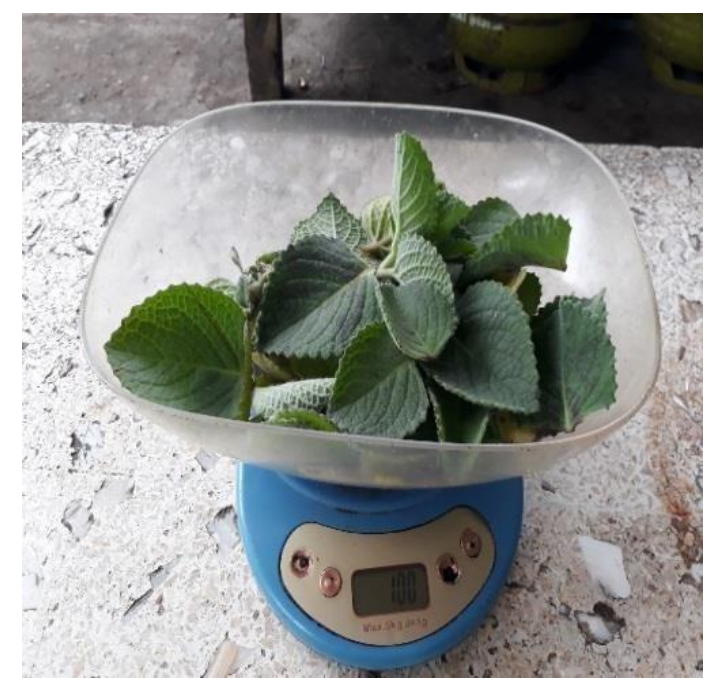

Gambar 1. Daun Jintan (Plectranthus amboinicus Lour Spreng)

Tanaman tersebut sangat mudah tumbuh dan tahan akan kekeringan dan kelembaban. Di dunia pengobatan disebut sebagai " mother of herb". Sebanyak $15 \mathrm{~g}$ daun jintan ditumbuk dan disaring cairannya untuk $1 \mathrm{~kg}$ ikan lele segar sesuai dengan hasil riset sebelumnya (Sundari et al., 2020; Sundari, Fitriadi, et al., 2019). Tidak disaring juga tidak masalah karena daun jintan adalah tanaman yang dapat dimPakan dan mengandung antioksidan yang menyehatkan, bahkan bisa menekan mikroorganisme pembusukan.

Kemudian dilakukan marinasi ikan lele segar dengan ekstrak daun jintan selama lebih kurang 30 menit agar bahan aktif daun jintan menyerap ke dalam ikan. Selanjutnya proses seperti yang biasa dilakukan dalam pembuatan abon, seperti pengukusan, pencabikan, pemberian bumbu, penggorengan, penirisan, penimbangan dan 
pengemasan. Seperti pada gambar berikut ini:

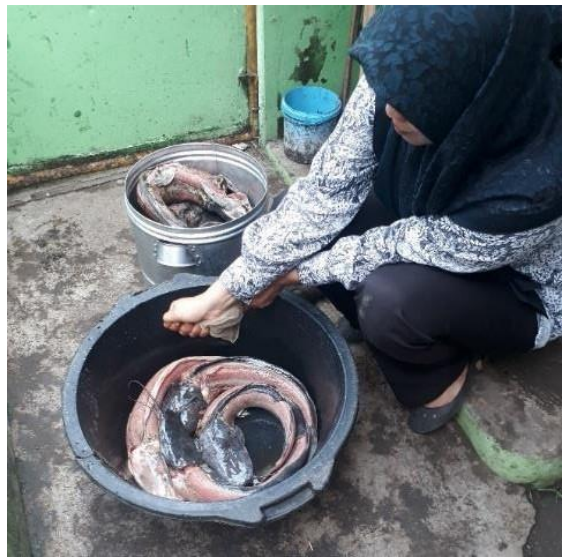

Gambar 3. Marinasi dengan Ekstrak Daun Jintan

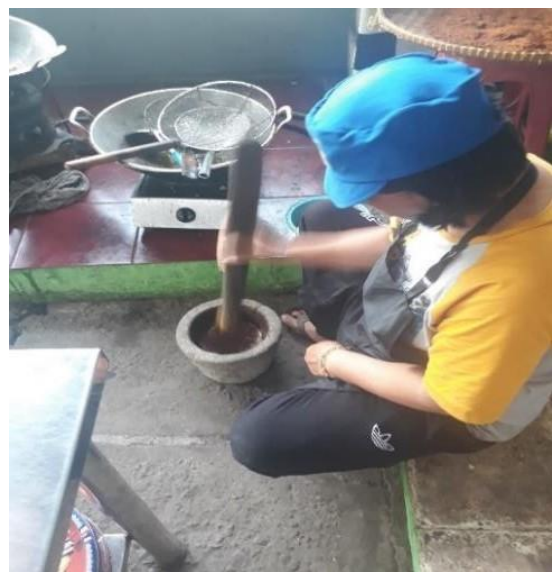

Gambar 4. Penghalusan bumbu Abon

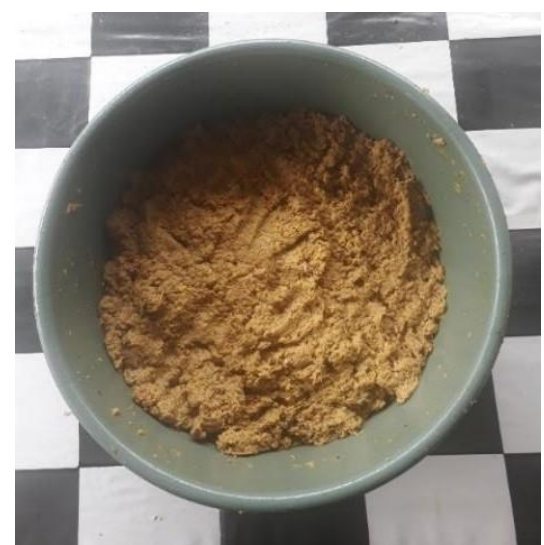

Gambar 5. Ikan lele kukus yang telah dicabik dan diberi bumbu

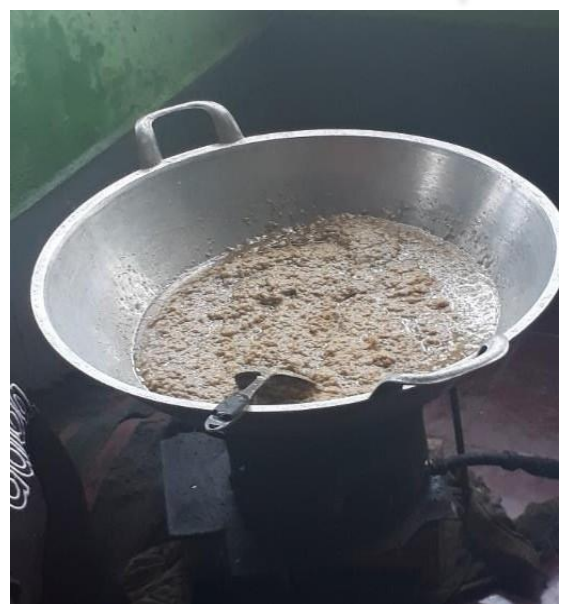

Gambar 6. Adonan digoreng

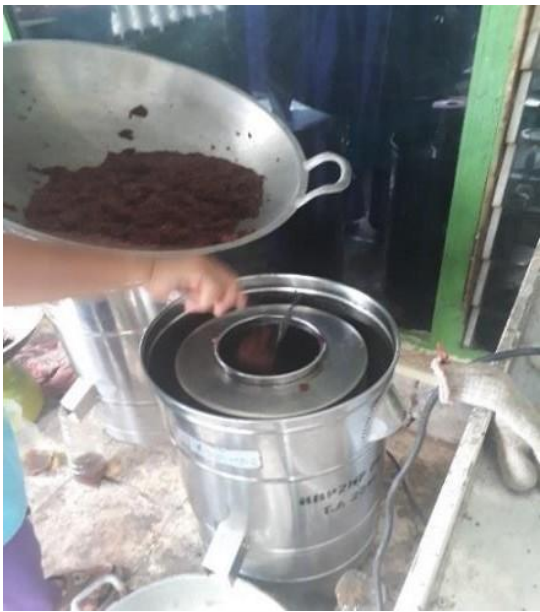

Gambar 7. Abon ditiriskan dengan mesin peniris (spinner)

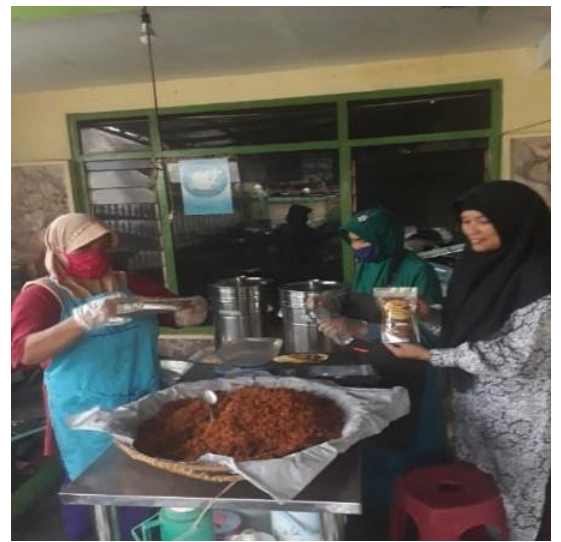

Gambar 8. Pendinginan Abon sebelum dikemas 
Evaluasi pelaksanaan program di di KWT Pengolah Ikan Jaya Mandiri menggunakan analisis komparasi Sign Test atau Binomial Test untuk mengetahui bagaimana perubahan yang terjadi pada kelompok sebelum dan sesudah diberi penyuluhan dan implementasi pembuatan abon ikan lele yang bebas bau amis. Persamaan yang digunaan adalah:

$$
Z=\frac{(x \pm 0.5)-0.5 N}{0.5 \sqrt{ } N}
$$

Dimana

$x+0.5$ digunakan bila $\mathrm{x}<0.5 \mathrm{~N}$

$x-0.5$ digunakan bila $\mathrm{x}>0.5 \mathrm{~N}$

$N=$ banyaknya tanda yang berbeda

$x=$ banyaknya tanda $(+)$ atau $(-)$ yang paling sedikit

$\mathrm{Z}=$ hasil evaluasi perubahan yang terjadi sebelum dan sesudah diberi penyuluhan.

\section{HASIL DAN PEMBAHASAN}

Hasil yang dicapai dalam kegiatan aplikasi proses pembuatan abon ikan bebas bau amis cukup menyenangkan bagi masyarakat karena mereka menganggap tidak sulit untuk diaplikasikan. Pemberdayaan masyarakat menjadi penting terutama dalam mengolah bahan pangan (Azis et al., 2019) khususnya ikan lele yang banyak terdapat di Jawa Barat. Melalui proses pengolahan, seperti dibuat abon ikan lele memberikan nilai tambah (Sundari et al., 2017) dan lebih menguntung jika dilakukan analisis nilai tambah (Syaputra et al., 2014).

Evaluasi pre-test dan posttest terhadap lima belas anggota masyarakat menghasilkan data yang disajikan pada tabel 1. Hasil perhitungan diperoleh: $\mathrm{N}=13, \mathrm{x}=2$, $\rho=0,0112$ menggunakan tabel $\mathrm{K}, \alpha=0,05$. Hasil analisis menunjukkan bahwa $\rho=$ $0,0112<\alpha=0,05$ terdapat perbedaan pemahaman materi sebelum dan sesudah diberi penyuluhan dan implementasi pembuatan abon ikan lele bebas amis.

Tabel 1. Hasil evaluasi penyuluhan

\begin{tabular}{ccc}
\hline Peserta & \multicolumn{2}{c}{ Nilai Evaluasi } \\
\cline { 2 - 2 } 1 & Pretest & Postest \\
\cline { 2 - 2 } 2 & 55 & 87 \\
2 & 40 & 73 \\
3 & 45 & 70 \\
4 & 37 & 68 \\
5 & 50 & 75 \\
6 & 46 & 65 \\
7 & 47 & 70 \\
8 & 52 & 71 \\
9 & 36 & 60 \\
10 & 60 & 60 \\
11 & 47 & 70 \\
12 & 56 & 55 \\
13 & 40 & 68 \\
14 & 58 & 56 \\
\hline
\end{tabular}

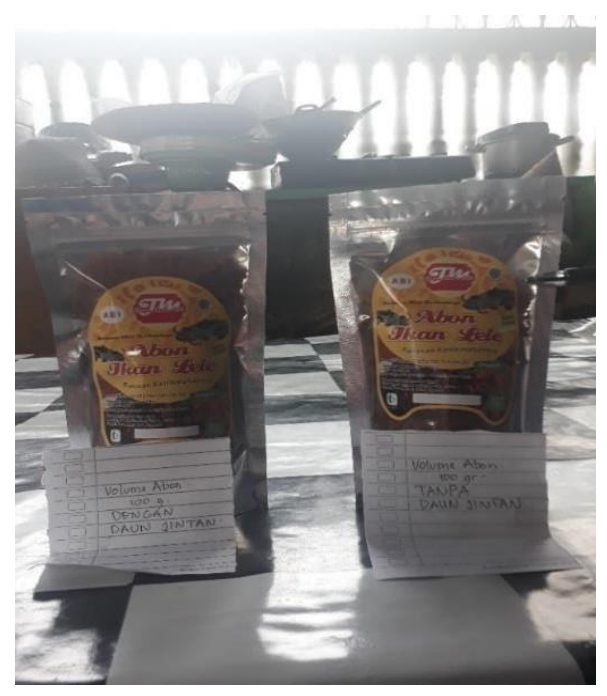

Gambar 1. Produk Abon Ikan Lele Original dan Bebas Amis

Abon ikan lele original tetap dibuat oleh KWT pengolah ikan untuk konsumen yang memang sukan denga ciri khas bau amisnya. Penyuluhan inovasi pembuatan abon ikan yang bebas bau amis diberikan untuk menjadikan varian produk abon ikan 


\section{JPM (Jurnal Pemberdayaan Masyarakat) \\ ISSN : 25411977 E- ISSN : 25411977 \\ Vol.6 No.1. 2021 \\ https://doi.org/10.21067/jpm.v6i1.5004}

lele yang baru untuk memperluas jaringan 
pasar dan konsumen yang menginginkan bau amisnya dihilangkan. Gambar 1 memperlihatkan dua produk abon ikan lele dengan pengolahan original dan yang diperkaya daun jintan. Keduan produk tersebut memperlihatkan hasil yang hampir sama. Namun dalam tiap kemasan dengan berat yang sama memperlihatkan volume yang berbeda. Dalam 100 gam kemasan abon ikan lele yang diberi tambahan daun jintan selain bebas amis juga lebih mengembang sehingga memenuhi kemasan. Hal ini menggembirakn anggota KWT karena satu kemasan dengan berat yang sama bisa penuh. Perlu dikaji mengapa terjadi perbedaan volume abon ikan original dan yang telah ditambahkan daun jintan. Sedangkan tekstur, struktur dan rasa sama. Dengan demikian hasil pengolahan ini memberikan kualitas yang lebih tinggi dengan mengembangnya volume dan bebas bau amis. Diharapkan tingkat keawetannya lebih tinggi dari yang original. Semua proses produk adalah alami tanpa pengawet.

Faktor-faktor yang menjadi penghambat adalah ketersediaan ikan lele secara kontinyu agar produksi dapat dilakukan terus. Selain itu system pemasaran dan adaptasi dengan teknologi yang saat ini sedang berlaku yaitu teknologi 4.0. Faktorfaktor pendukung dalam kegiatan ini adalah terobosan baru dimana daun jintan yang biasanya dipakai untuk pengobatan, sebagai antiokasidan untuk mahluk hidup baik manusia dan hewan atau mengendalikan hama, maka di sini sangat efektif digunakan untuk bahan pangan.

\section{PENUTUP}

\section{Simpulan}

Dari hasil pengabdian ini dapat diambil kesimpulan bahwa abon ikan yang telah ditambahkan daun jintan memilikilevel aroma bau amis yang rendah sehingga lebih disukai oleh konsumen yang menginginkan abon ikan bebas amis, Dengan demikian KWT dapat mengatasi keluhan konsumen dalam aroma bau amis ikan dengan pemberian daun jintan dengan volume yang lebih banyak dan kualitas lebih tinggi. Di samping itu, implementasi inovasi ini cukup mudah diterima dan dilakukan oleh masyarakat. Hambatannya adalah sirkulasi permodalan dan pemasaran. KWT juga keberatan untuk meminjam modal dari Bank karena yang menjadi hambatan adalah perputarannya.

\section{Saran}

Perlu adanya jaringan pemasaran yang lebih kekinian dan berteknologi seperti startup, market place dan jual lepas. Karena dengan system konsinyasi membuat sirkulasi modal tersangkut. Kegiatan pengabdian ini akan berkelanjutan sebagai Desa binaan untuk memeprluas jaringan permintaan dan pemasaran.

\section{Ucapan Terima Kasih}

Terimakasih kepada lembaga Universitas Perjuangan yang telah mendukung pendanaan kegiatan pengabdian ini.

\section{E. DAFTAR PUSTAKA}

Azis, A., Safitri, E., Irmawati, \& Suparmin. (2019). Pemberdayaan Masyarakat Berbasis Ketahan Pangan melalui Pengolahan Abon dari Ikan Nila di Desa Pringarata Kecamatan Pringarata Kabupaten Lombok Tengah. Jurnal Warta Desa, 1(1), 75-79.

Ismail, A. M., \& Putra, D. E. (2017). Inovasi Pembuatan Abon Ikan Cakalang dengan Penambahan Jantung Pisang. Agritech: Jurnal Fakultas Pertanian Universitas Muhammadiyah Purwokerto, 19(1), 4554. 
Kotler. (2011a). Manajemen Pemasaran di Indonesia: Analisis, Perencanaan, Implementasi dan Pengendalian. In Jakarta : Penerbit Salemba Empat.

Kotler. (2013). Manajemen Pemasaran Jilid 2. In Penerbit Erlangga.

Kotler, P. (2011b). Reinventing marketing to manage the environmental imperative. In Journal of Marketing.

Kotler, P., \& Keller, K. L. (2016). A Framework for Marketing Management. In Marketing Management.

Pratama, R. I., Rostini, I., \& Lviawaty, E. (2018). Volatile components of raw Patin Catfish (Pangasius hypophthalmus) and Nile Tilapia (Oreochromis niloticus). IOP Conference Series: Earth and Environmental Science, 176(1).

Prataman, R. I., Rostini, I., \& Rochima, E. (2018). Profil Asam Amino, Asam Lemak dan Komponen Volatil Ikan Gurame Segar (Osphronemus gouramy) dan Kukus. Jurnal Pengolahan Hasil Perikanan Indonesia, 21(2), 219-232.

Sundari, R. S., Fitriadi, B. W., Kusmayadi, A., Arshad, A., \& Priyanto, Y. A. (2019). Aplikasi Teknologi Pembuatan Abon Ikan Antioksidan Daun Jintan. Jurnal KUAT, 1(3), 181-185.

Sundari, R. S., Kusmayadi, A., \& Umbara, D. S. (2017). Komparasi nilai Tambah Agroindustri Abon Inkan Lele dan Ikan Patin di Tasikmalaya. Jurnal Pertanian Agros, 19(1), 45-54.
Sundari, R. S., Umbara, D. S., \& Arshad, A. (2020). Perilaku Konsumen terhadap Keputusan Mengkonsumsi Produk Agroindustri Abon Ikan Lele Original. Mimbar Aagribisnis: Jurnal Pemikiran Masyarakat Ilmiah Berwawasan Agribisnis, 6(2), 833-842.

Sundari, R. S., Umbara, D. S., Fitriadi, B. W., \& Sulaeman, M. (2019). Consumer Preference on Catfishes (Patin and Lele) Sweetmeat Product. Journal of Physics: Conference Series, 1179(1).

Syaputra, E., Lubis, S. N., \& Iskandarini. (2014). Analisis Nilai Tambah Produk Olahan Bolu dan Brownies Rambutan. USU, $\quad 1-12$. https://media.neliti.com/media/publicati ons/94703-ID-analisis-nilai-tambahproduk-olahan-bolu.pdf 